\title{
Preservation of Chirality and Polarity between Chiral and Polar Building Units in the Solid State
}

\author{
Romain Gautier and Kenneth R. Poeppelmeier* \\ Northwestern University, 2145 Sheridan Road, Evanston, Illinois 60201-3113, United States
}

Supporting Information
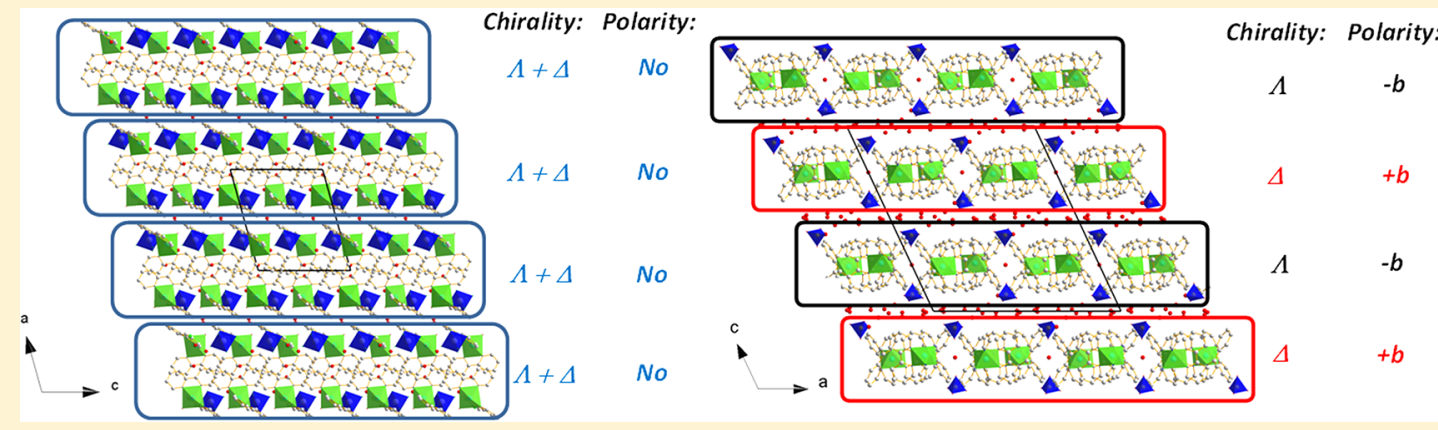

ABSTRACT: The new lamellar phases $\left[\mathrm{Zn}\left(2,2^{\prime} \text {-bpy }\right)_{2}\left(\mathrm{H}_{2} \mathrm{O}\right)_{2}\right]\left(\mathrm{ZrF}_{6}\right) \cdot 3 \mathrm{H}_{2} \mathrm{O}(\mathrm{I})$ and $\left[\mathrm{Ni}\left(2,2^{\prime} \text {-bpy }\right)_{3}\right]\left(\mathrm{MoO}_{2} \mathrm{~F}_{4}\right) \cdot 5 \mathrm{H}_{2} \mathrm{O}(\mathrm{II})(\mathrm{bpy}$ $=$ bipyridine), which are built from a chiral cation and respectively an inherently nonpolar and a polar anion, provide two contrasting structures with respect to chirality and polarity in the solid state. Each nonpolar layer of I contains enantiomers of both handednesses; conversely, each layer of II contains only a $\Delta$ or $\Lambda$ enantiomer and polar anions oriented along the $b$ or $-b$ axes. A comparison with previously reported structures reveals which combinations and interactions between chiral and polar basic building units can preserve elements of polarity and chirality in the solid state.

\section{INTRODUCTION}

Chiral and polar basic building units (BBUs) provide starting blocks for the synthesis of noncentrosymmetric (NCS) structures that have potential physical properties, for example, piezoelectricity, optical activity, and ferroelectricity. ${ }^{1}$ However, the use of chiral BBUs is limited in exploratory synthesis because of the cost of enantiomeric purification. Moreover, the arrangement of polar BBUs remains difficult to control or predict, and centrosymmetric structures are often observed. Recently, several authors have reported the use of singleenantiomorph BBUs (which can only crystallize in a chiral space group) combined with polar BBUs to prevent the net dipole moment cancellation through inversion centers. ${ }^{2-6}$ This technique does allow some level of control over the alignment of the polar BBUs; however, the polarity cannot be guaranteed because chiral and nonpolar structures often result. This strategy is also of limited use in exploratory synthesis because of the cost of enantiomeric purification. A significant improvement in the design of NCS materials would also be gained if racemic BBUs instead of single-enantiomorph BBUs could be used to align the polar BBUs. The influences of polar BBUs on chiral resolution and chiral BBUs on the alignment of polar BBUs also need to be investigated. To further develop this topic, materials built from racemic cations $\left[\mathrm{M}^{\prime}\left(2,2^{\prime}\right.\right.$ bpy $\left.)_{y}\left(\mathrm{H}_{2} \mathrm{O}\right)_{6-2 y}\right]^{2+}$ (bpy $=$ bipyridine $)$ and polar anions $\left[\mathrm{MO}_{x} \mathrm{~F}_{6-x}\right]^{2-}$ were targeted to investigate the influence that each of these BBUs has on the other when a crystalline phase forms.

\section{EXPERIMENTAL SECTION}

Caution! Hydrofluoric acid is toxic and corrosive! It must be handled with extreme caution and the appropriate protective gear. ${ }^{7-9}$

Synthesis. Both of the title compounds were synthesized by a hydrothermal method with similar amounts of starting materials. For the preparation of $\left[\mathrm{Zn}\left(2,2^{\prime} \text {-bpy }\right)_{2}\left(\mathrm{H}_{2} \mathrm{O}\right)_{2}\right]\left(\mathrm{ZrF}_{6}\right) \cdot 3 \mathrm{H}_{2} \mathrm{O}(\mathrm{I})$, a mixture of $\mathrm{ZrO}_{2}$ (1.67 mmol, Aldrich 99.99\%), $\mathrm{ZnO}$ (1.67 mmol, Alpha Aeasar 99.99\%), 2,2'-bipyridine (2.56 mmol, Aldrich 99\%), deionized water $(5.5 \mathrm{mmol})$, and $48 \%$ aqueous $\mathrm{HF}(27.8 \mathrm{mmol}$, Aldrich) was placed in a Teflon pouch. ${ }^{10}$ For the preparation of $\left[\mathrm{Ni}\left(2,2^{\prime} \text {-bpy }\right)_{3}\right]$ $\left(\mathrm{MoO}_{2} \mathrm{~F}_{4}\right) \cdot 5 \mathrm{H}_{2} \mathrm{O}(\mathrm{II})$, a mixture of $\mathrm{MoO}_{3}(1.67 \mathrm{mmol}$, Alfa Aeasar 99.95\%), $\mathrm{NiO}$ (1.67 mmol, Aldrich 99.99\%), 2,2'-bipyridine (2.56 mmol, Aldrich $99 \%)$, deionized water $(5.5 \mathrm{mmol})$, and $48 \%$ aqueous HF (27.8 mmol, Aldrich) was loaded to another pouch. The pouches were placed into a $125 \mathrm{~mL}$ Parr autoclave with a backfill of $45 \mathrm{~mL}$ of distilled water, heated to $150{ }^{\circ} \mathrm{C}$ for $24 \mathrm{~h}$, and slowly cooled to room temperature at $0.1{ }^{\circ} \mathrm{C} / \mathrm{min}$. Single crystals were recovered by vacuum filtration in air in $25 \%$ yield based on $\mathrm{Zr}$ for compound I and in $34 \%$ yield based on Mo for compound II. The elemental content of each compound was confirmed with energy-dispersive X-ray spectroscopy ( $\mathrm{Mo} / \mathrm{Ni}$ in compound I, 0.56/0.44; $\mathrm{Zr} / \mathrm{Zn}$ in compound II, 0.45/ 0.55 ). The role of HF in solution is multiple: (i) it lowers the $\mathrm{pH}$ of the reaction ( $\mathrm{pH}$ below 1 before and after the reaction), (ii) it is the precursor of fluoride, and (iii) it ionizes the precursors. A low $\mathrm{pH}$ is important to stabilize the cationic and anionic species of both $\mathbf{I}$ and II. Materials such as $\mathrm{Zn}(\mathrm{pyz})\left(\mathrm{H}_{2} \mathrm{O}\right)_{2} \mathrm{MoO}_{2} \mathrm{~F}_{4}$ and $\mathrm{Ni}\left(\mathrm{H}_{2} \mathrm{O}\right)_{6}\left[\mathrm{ZrF}_{6}\right]$ with similar $\left[\mathrm{ZrF}_{6}\right]^{2-}$ and $\left[\mathrm{MoO}_{2} \mathrm{~F}_{4}\right]^{2-}$ anions were also previously reported

Received: April 25, 2012

Published: September 27, 2012 
to be synthesized in acidic conditions. ${ }^{1-13}$ Three ratios of $2,2^{\prime}$ bipyridine/metal have been tested (1.5:1, 2:1, and 3:1) for the hydrothermal syntheses of I and II. Powder X-ray diffraction shows only the one product for all three compositions, confirming stabilization of $\left[\mathrm{Zn}\left(2,2^{\prime}-\text { bpy }\right)_{2}\left(\mathrm{H}_{2} \mathrm{O}\right)_{2}\right]^{2+}$ or $\left[\mathrm{Ni}\left(2,2^{\prime}-\mathrm{bpy}\right)_{3}\right]^{2+}$ in different bipyridine/metal stoichiometry amounts.

X-ray Diffraction. Single-crystal X-ray diffraction experiments were conducted at $100 \mathrm{~K}$ using a Bruker APEX II CCD diffractometer with monochromated Mo $\mathrm{K} \alpha$ radiation $(\lambda=0.71073 \AA$ ). The crystalto-detector distance was $60 \mathrm{~mm}$, and data integrations were made using the SAINT-PLUS program. ${ }^{14}$ Absorption corrections were applied with $S A D A B S{ }^{15}$ The structures were determined by means of direct methods, completed by Fourier difference syntheses with SIR97, and then refined using SHELXL-97. ${ }^{16,17}$ Additional symmetry elements were checked using the program PLATON. ${ }^{18}$ Anisotropic displacement parameters were refined using SHELXL-97. H atoms of $2,2^{\prime}$-bipyridine molecules were constrained to ride at distances of 0.93 $\AA$ from the associated $\mathrm{C}$ atoms with $U_{\text {iso }}(\mathrm{H})=1.5 U_{\text {eq }}(\mathrm{C})$. Crystallographic data are reported in Table 1.

Table 1. Crystal Data and Summary of Data Collections, Structure Solutions, and Refinements for I and II

\begin{tabular}{lll} 
& \multicolumn{1}{c}{ compound I } & compound II \\
space group & $P 2_{1} / c($ No. 14) & C2/c (No. 15) \\
$a(\AA)$ & $14.8700(5)$ & $23.3152(8)$ \\
$b(\AA)$ & $13.7295(5)$ & $14.8849(5)$ \\
$c(\AA)$ & $13.1071(5)$ & $19.5430(7)$ \\
$\beta(\mathrm{deg})$ & $105.561(2)$ & $102.9732(14)$ \\
$V\left(\AA^{3}\right)$ & $2577.83(16)$ & $6609.2(4)$ \\
$T(\mathrm{~K})$ & $100(2)$ & $100(2)$ \\
$Z$ & 4 & 8 \\
$\max \theta(\mathrm{deg})$ & 30.5 & 30.6 \\
$\lambda(\mathrm{Mo} \mathrm{K} \alpha)(\AA)$ & 0.71073 & 0.71073 \\
$\left.\rho_{\text {calc }}(\mathrm{g} \mathrm{cm})^{-3}\right)$ & 1.724 & 1.631 \\
$R_{\text {int }}$ & 0.060 & 0.029 \\
$\mathrm{R} 1$ & 0.050 & 0.037 \\
wR2 & 0.107 & 0.108 \\
$\mathrm{GOF}$ & 1.01 & 1.05
\end{tabular}

IR Measurements. IR spectra were collected for compounds I and II on a Bruker 37 Tensor FTIR equipped with an ATR germanium cell attachment. A background spectrum was subtracted, and 360 scans with $1 \mathrm{~cm}^{-1}$ resolution were averaged.

\section{RESULTS AND DISCUSSION}

Structure Description. Compounds I and II are built from isolated late-transition-metal-centered cations and early-transition-metal-centered anions linked through hydrogen-bonding interactions. They both crystallize in centrosymmetric space groups $\left(P 2_{1} / c\right.$ and $C 2 / c$ for compounds I and II, respectively). Cationic and anionic BBUs pack into layers with water molecules within the interlamellar space. Both I and II contain five water molecules with different coordination motifs. In I, six-coordinate $\mathrm{Zn}^{2+}$ is coordinated to two $2,2^{\prime}$-bipyridyne ligands; two water molecules complete its octahedral environment. There are three water molecules in the interlamellar space. In II, six-coordinate $\mathrm{Ni}^{2+}$ is coordinated to three $2,2^{\prime}$ bipyridyne ligands and the five water molecules are in the interlamellar space.

In compound $\mathrm{I}$, the asymmetric unit contains one $\left[\mathrm{ZrF}_{6}\right]^{2-}$ anion, one $\left[\mathrm{Zn}\left(2,2^{\prime} \text {-bpy }\right)_{2}\left(\mathrm{H}_{2} \mathrm{O}\right)_{2}\right]^{2+}$ cation (Figure 1a), and three uncoordinated water molecules. The $\mathrm{Zr}-\mathrm{F}$ internuclear distances are in the range 1.9810(25) $\AA \leq d_{\mathrm{Zr}-\mathrm{F}} \leq 2.0154(23)$ $\AA$. The $\mathrm{Zn} 1-\mathrm{Ow} 1$ and $\mathrm{Zn} 1-\mathrm{Ow} 2$ bond distances are
$2.0986(23)$ and 2.0878(28) $\AA$, respectively. The bond lengths between $\mathrm{Zn} 1$ and $\mathrm{N}$ atoms of 2,2'-bipyridine molecules are between $2.115(3)$ and 2.1839(28) Å. To our knowledge, only three structures have been reported with the cation $\left[\mathrm{Zn}\left(2,2^{\prime}\right.\right.$ bpy $\left.)_{2}\left(\mathrm{H}_{2} \mathrm{O}\right)_{2}\right]^{2+} .{ }^{19,20}$ The internuclear distances $[2.106(4) \AA \leq$ $d_{\mathrm{Zn}-\mathrm{N}} \leq 2.175(2) \AA$ and 2.064(6) $\left.\AA \leq d_{\mathrm{Zn}-\mathrm{O}} \leq 2.1450(29) \AA\right]$ agree with those reported here for compound $I$.

In compound II, the asymmetric unit contains one $\left[\mathrm{MoO}_{2} \mathrm{~F}_{4}\right]^{2-}$ anion, one $\left[\mathrm{Ni}\left(2,2^{\prime}-\mathrm{bpy}\right)_{3}\right]^{2+}$ cation (Figure $1 \mathrm{~b}$ ), and five free water molecules. The $\left[\mathrm{MoO}_{2} \mathrm{~F}_{4}\right]^{2-}$ anion is partially disordered. The shortest bond Mo1-X1 $[\mathrm{X}=\mathrm{O} / \mathrm{F}$; $1.6668(21) \AA]$ is in a trans position to the longest bond of Mo1-X4 [2.1766(16) ̊]. The equatorial bond distances vary from $1.7927(19)$ to $2.0036(15) \AA$. The net dipoles generated by the off-centering of $\left[\mathrm{MoO}_{2} \mathrm{~F}_{4}\right]^{2-}$ octahedra cancel each other. ${ }^{21}$ The bonds from $\mathrm{Nil}$ to $\mathrm{N}$ atoms of $2,2^{\prime}$-bipyridine molecules are between 2.0766(17) and 2.0958(20) A. [ $\mathrm{Ni}\left(2,2^{\prime}\right.$ bpy $\left.)_{3}\right]^{2+}$ is consistent with cations previously reported in the literature: the bond lengths between $\mathrm{Ni}$ and $\mathrm{N}$ atoms of 2,2 'bipyridine molecules vary from $2.0801(2)$ and 2.1026(4) $\AA$ in the structure of $\left[\mathrm{Ni}\left(2,2^{\prime}-\mathrm{bpy}\right)_{3}\right]\left(\mathrm{SO}_{4}\right) \cdot 7.5 \mathrm{H}_{2} \mathrm{O} .{ }^{22}$ In the structure of $\left[\mathrm{Ni}\left(2,2^{\prime}-\mathrm{bpy}\right)_{3}\right]\left(\mathrm{S}_{2} \mathrm{O}_{3}\right) \cdot 7 \mathrm{H}_{2} \mathrm{O},{ }^{23}$ the Ni-N internuclear distances are in the range $2.0859(42) \AA \leq d_{\mathrm{Ni}-\mathrm{N}} \leq$ 2.1006(29) A.

IR Measurement. FTIR spectra of compounds I and II are shown in Figure $\mathrm{S} 1$ in the Supporting Information. Both spectra reveal similarities because of the presence of 2,2 'bipyridine and water molecules in both structures. Thus, IR bands at 1440 and $1020 \mathrm{~cm}^{-1}$ (2,2'-bipyridine molecules) and in the range $3000-3500 \mathrm{~cm}^{-1}(\mathrm{OH}$ stretching of water molecules) can be observed. ${ }^{24}$ In compound II, IR bands at 922 and $899 \mathrm{~cm}^{-1}$ are the stretching frequencies of cis- $\mathrm{MoO}_{2}{ }^{25}$ This measurement also further confirms the presence of a disordered $\left[\mathrm{MoO}_{2} \mathrm{~F}_{4}\right]^{2-}$ anion in II.

Formation of Chiral and Polar Units. In compounds I and II, the late transition metals coordinate to bidendate 2,2 ' bipyridine ligands to create the chiral BBUs. The handednesses of these chiral units are distinguished by the Greek letters $\Delta$ and $\Lambda$ (Figure 1). The $\mathrm{Zn}^{2+}$ cations in $\mathbf{I}$ are coordinated to two $2,2^{\prime}$-bipyridine ligands and two water molecules, which confers the $\mathrm{C}_{2}$ symmetry to the $\left[\mathrm{Zn}\left(2,2^{\prime}-\mathrm{bpy}\right)_{2}\left(\mathrm{H}_{2} \mathrm{O}\right)_{2}\right]^{2+}$ BBUs. The $\mathrm{Ni}^{2+}$ cations in II are coordinated to three $2,2^{\prime}$-bipyridine ligands, which confers the $D_{3}$ symmetry to the $\left[\mathrm{Ni}\left(2,2^{\prime}\right.\right.$ bpy $\left.)_{3}\right]^{2+}$ BBUs.

The polarity of the early-transition-metal-centered anions $\left[\mathrm{MO}_{x} \mathrm{~F}_{6-x}\right]^{2-}$ (symmetry $\mathrm{C}_{2 v}$ ) is induced by the off-centering distortion of the transition metal " $\mathrm{M}$ " in their octahedral environment. Two categories of distortions can be distinguished: the primary distortion arising from electronic effects such as $\mathrm{d} \pi-\mathrm{p} \pi$ metal-oxide orbital interactions arising from second-order Jahn-Teller effects and the weaker secondary distortion arising from interactions between the $\left[\mathrm{MO}_{x} \mathrm{~F}_{6-x}\right]^{2-}$ anion and its surrounding environment. ${ }^{26,27}$ The $\left[\mathrm{ZrF}_{6}\right]^{2-}$ anions in compound $\mathbf{I}$ are inherently nonpolar (symmetry $O_{h}$ ), where the $\mathrm{Zr}-\mathrm{F}$ bonds are equivalent. The interactions of these anions with the extended structure, however, lead to a small distortion. On the other hand, the $\left[\mathrm{MoO}_{2} \mathrm{~F}_{4}\right]^{2-}$ anions in compound II are distorted owing to both primary and secondary distortions.

Relation between the Handedness of Chiral Units and the Orientation of Polar Units. In I, each layer contains $\left[\mathrm{Zn}\left(2,2^{\prime} \text {-bpy }\right)_{2}\left(\mathrm{H}_{2} \mathrm{O}\right)_{2}\right]^{2+}$ cations of both handednesses $(\Delta$ and $\Lambda)$ and the weak polarities of the individual $\left[\mathrm{ZrF}_{6}\right]^{2-}$ anions 
(a)

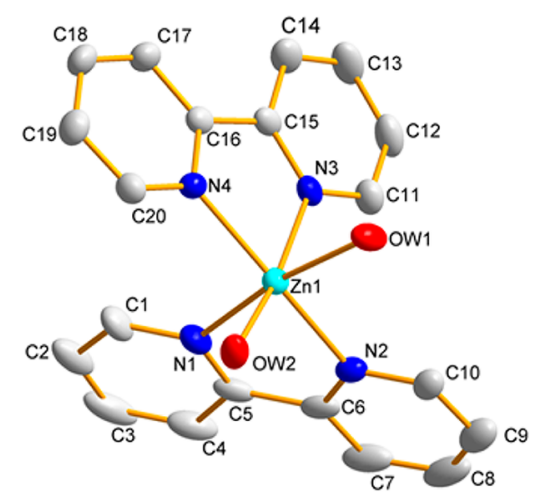

Aenantiomer

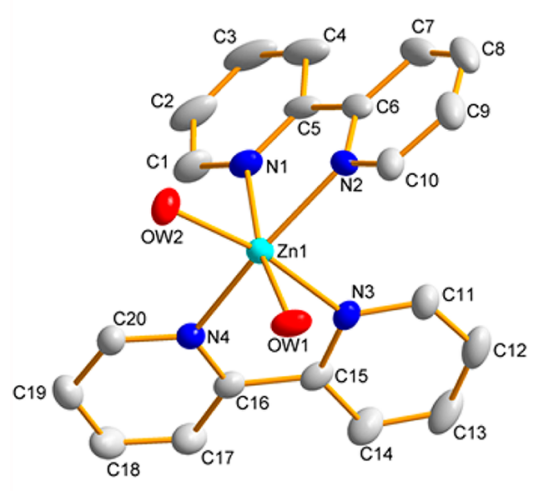

$\Lambda$ enantiomer (b)

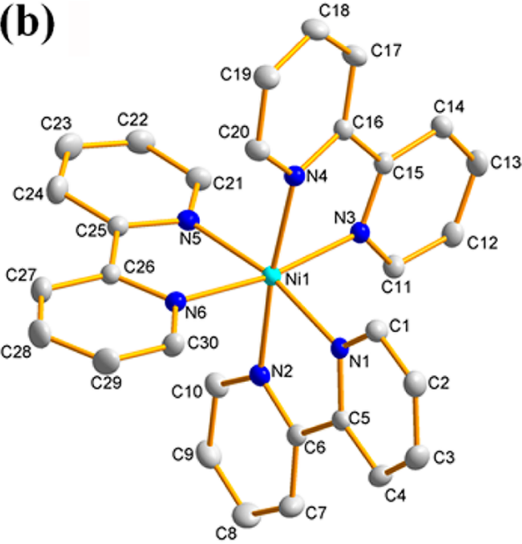

$\Delta$ enantiomer

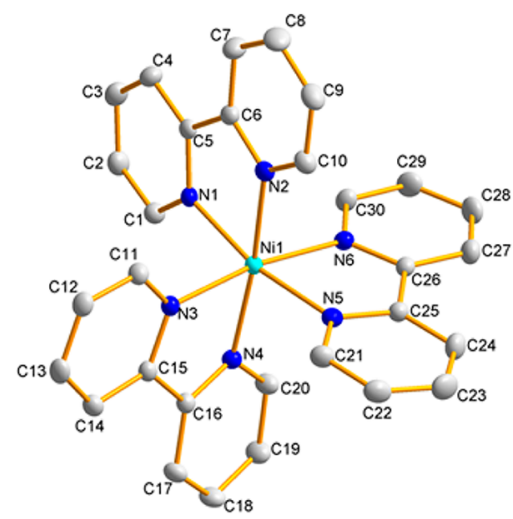

$\Lambda$ enantiomer

Figure 1. Representation of (a) the chiral $\left[\mathrm{Zn}\left(2,2^{\prime} \text {-bpy }\right)_{2}\left(\mathrm{H}_{2} \mathrm{O}\right)_{2}\right]^{2+}$ cation with $\mathrm{C}_{2}$ symmetry in compound $\mathbf{I}$ and $(\mathrm{b})$ the chiral $\left[\mathrm{Ni}\left(2,2^{\prime} \text {-bpy }\right)_{3}\right]^{2+}$ cation with $D_{3}$ symmetry in compound II. $\mathrm{H}$ atoms have been omitted for clarity. Displacement ellipsoids are drawn at the $50 \%$ probability level.

created by secondary distortions cancel each other. This absence of net polarity within each layer is accompanied by the absence of a unique handedness of the cations (Figure 2). In contrast, the $3 \mathrm{D} \quad\left[\mathrm{Zn}\left(2,2^{\prime}-\mathrm{bpy}\right)_{2}\left(\mathrm{H}_{2} \mathrm{O}\right)_{2}\right]$ $\left[\mathrm{Cr}_{2}(\mathrm{OH})_{2}(\mathrm{nta})_{2}\right] \cdot 7 \mathrm{H}_{2} \mathrm{O}$ structure, which is a previously reported compound with $\left[\mathrm{Zn}\left(2,2^{\prime}-\mathrm{bpy}\right)_{2}\left(\mathrm{H}_{2} \mathrm{O}\right)_{2}\right]^{2+}$ BBUs, crystallizes in the polar, chiral space group $P 2_{1}$ (Figure 3$){ }^{19}$ Within this NCS structure, the chiral $\left[\mathrm{Zn}\left(2,2^{\prime} \text {-bpy }\right)_{2}\left(\mathrm{H}_{2} \mathrm{O}\right)_{2}\right]^{2+}$ BBUs exhibit only one handedness and the polar $\left[\mathrm{Cr}_{2}(\mathrm{OH})_{2}(\mathrm{nta})_{2}\right]^{2-}$ anionic BBUs with the symmetry $C_{1}$ are oriented along the polar axis. The comparison between the two structures and the investigation of the symmetry operations in compound I point out the role that inversion centers have, simultaneously, on the antiparallel alignment of polar BBUs and the inversion of the handnesses of chiral BBUs. Thus, the chiral resolution can prevent the presence of inversion centers that antialign the polar BBUs, while the alignment of polar BBUs can prevent the presence of inversion centers that reverse the handedness of chiral BBUs. Some authors have reported the use of enantiomorph BBUs to prevent net dipole moment cancellation through an inversion center, but the influence of the alignment of polar BBUs on the chiral resolution of a racemic mixture was never investigated. ${ }^{2-6}$

In II, the layers consist of $\left[\mathrm{Ni}\left(2,2^{\prime}-\mathrm{bpy}\right)_{3}\right]^{2+} \mathrm{BBUs}$ of one handedness (either $\Delta$ or $\Lambda$ ) and the local distortions of the polar $\left[\mathrm{MoO}_{2} \mathrm{~F}_{4}\right]^{2-}$ anions in each layer partially align along $b$ or $-b$ (Figure 4 ). The chiralities and polarities of each layer are reversed by inversion centers located within the interlamellar space. Enantiomers with different handednesses also orient the polar units in opposing directions. Compound II is similar to the previously reported $\left[\mathrm{Ni}\left(2,2^{\prime} \text {-bpy }\right)_{3}\right]\left(\mathrm{SO}_{4}\right) \cdot 7.5 \mathrm{H}_{2} \mathrm{O}$ (Figure $5),\left[\mathrm{Ni}\left(2,2^{\prime} \text {-bpy }\right)_{3}\right]\left(\mathrm{S}_{2} \mathrm{O}_{3}\right) \cdot 7 \mathrm{H}_{2} \mathrm{O}$, and $\left[\mathrm{Ni}\left(2,2^{\prime} \text {-bpy }\right)_{3}\right]-$ $\left(\mathrm{CrO}_{4}\right) \cdot 7.5 \mathrm{H}_{2} \mathrm{O}$ that crystallize in the same space group $\mathrm{C} 2 /$ c. $^{22,23,28}$ These structures are also built of layers of $\left[\mathrm{Ni}\left(2,2^{\prime}\right.\right.$ bpy $\left.)_{3}\right]^{2+}$ BBUs of unique handedness and the polarities of the $\mathrm{SO}_{4}{ }^{2-}, \mathrm{S}_{2} \mathrm{O}_{3}{ }^{2-}$, or $\mathrm{CrO}_{4}{ }^{2-}$ anions are successively aligned along $b$ and $-b$. Analysis of the $\left[\mathrm{Ni}\left(2,2^{\prime}-\mathrm{bpy}\right)_{3}\right]\left(\mathrm{CrO}_{4}\right) \cdot 7.5 \mathrm{H}_{2} \mathrm{O}$ structure, in which $\mathrm{H}$ atoms were determined by a difference Fourier map, reveals the important role of the interlamellar water molecules on the antiparallel alignment of the anions. Through the bonding of anions of different layers, the interlamellar water molecules reverse the polarity and chirality of adjacent layers and induce the inversion center in these materials. These examples also serve to illustrate that chiral BBUs with a unique handedness provide an acentric environment to align polar BBUs $\left(\left[\mathrm{MoO}_{2} \mathrm{~F}_{4}\right]^{2-}, \mathrm{SO}_{4}{ }^{2-}, \mathrm{S}_{2} \mathrm{O}_{3}{ }^{2-}\right.$, or $\mathrm{CrO}_{4}{ }^{2-}$ anions) along the same direction. In these structures, water molecules in the interlamellar space interrupt the propagation of noncentrosymmetry.

Various authors have described the influence of chirality on the polarity in the solid state. ${ }^{2-6,29}$ Veltman et al. mentioned that a cancellation mechanism of the local distortions of $\mathrm{MO}_{6}$ octahedra via the center of inversion cannot occur when an enantiomerically pure source of chiral amines is used. Thus, one can also consider that cancellation mechanisms via mirror planes could not occur. Other symmetry operations, however, 


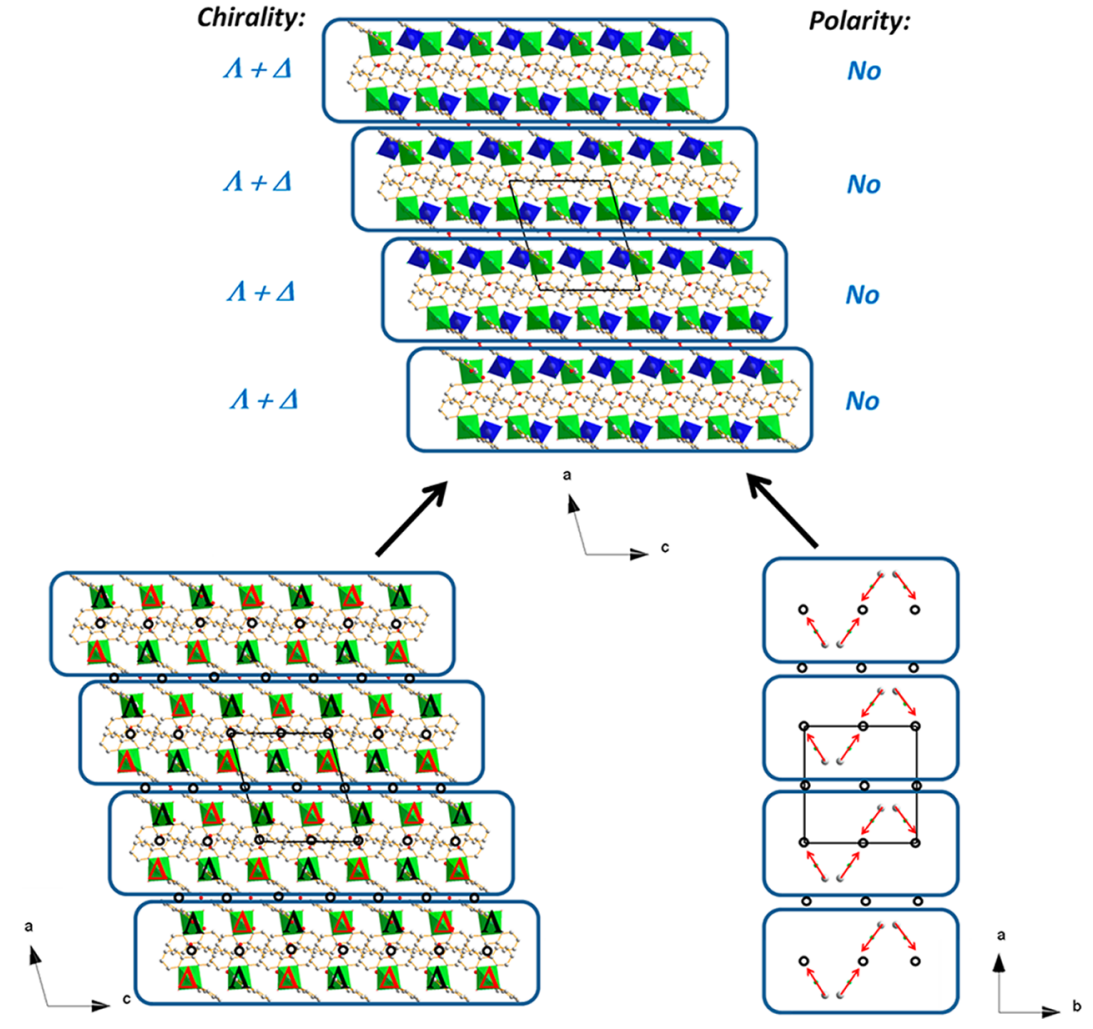

Figure 2. Chirality and polarity in compound I. The handedness of chiral cations is represented by the Greek letter $\Delta$ or $\Lambda$. $\mathrm{H}$ atoms have been removed for clarity. Green octahedra represent late-transition-metal-centered units. Blue octahedra represent early-transition-metal-centered units. Black circles represent the inversion centers.

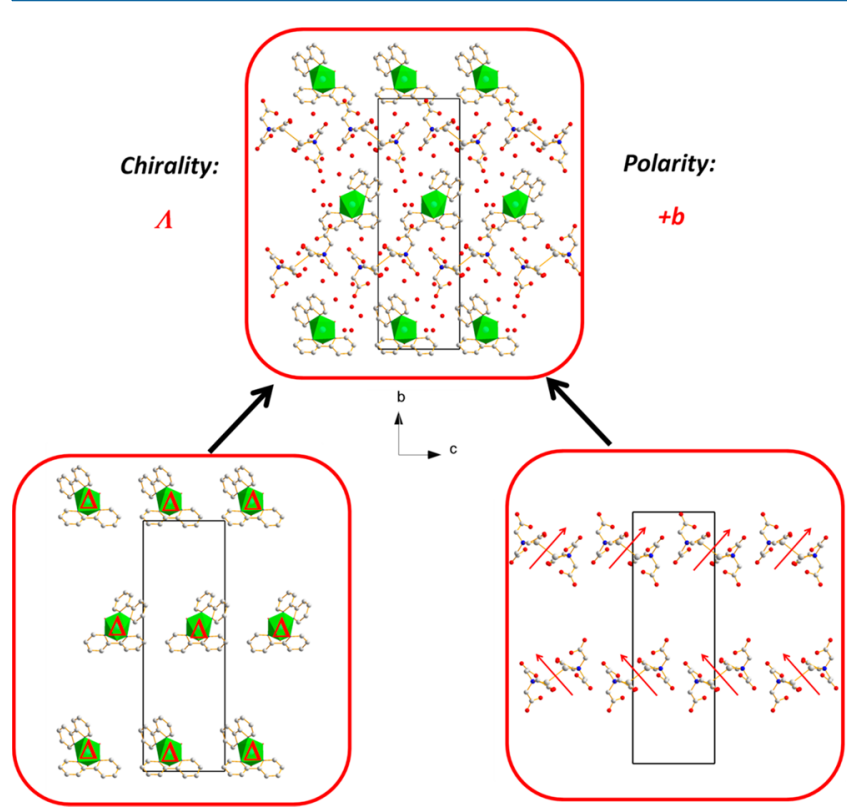

Figure 3. Chirality and polarity in $\left[\mathrm{Zn}\left(2,2^{\prime}-\mathrm{bpy}\right)_{2}\left(\mathrm{H}_{2} \mathrm{O}\right)_{2}\right]$ $\left[\mathrm{Cr}_{2}(\mathrm{OH})_{2}(\mathrm{nta})_{2}\right] \cdot 7 \mathrm{H}_{2} \mathrm{O}{ }^{19}$ The handedness of chiral cations is represented by the Greek letter $\Delta$, and the polarity of the anions is aligned along $b$. Green octahedra represent late-transition-metalcentered units.

such as rotation axes can cancel the local distortions of $\mathrm{MO}_{6}$ octahedra. Analyses of the structures I and II and a comparison with other similar structures also reveal a new feature: polar BBUs tend to be aligned, and chiral BBUs are likely to be of unique handedness in these acentric environments. The presence of chiral BBUs with unique handedness offers an acentric environment suitable for a partial or total alignment of the polar anions. The presence of the opposite handedness, however, provides an acentric environment for the partial or total alignment of the polar anions along the opposite direction. Nonetheless, the alignment of acentric BBUs favors the presence of chiral units with a unique handedness. Chiral and polar BBUs must be in contact to have an influence on the other. Thus, the packing of layers in II does not allow the propagation of noncentrosymmetry from one layer to the adjacent ones (Figure 4). However, the interactions between polar $\left[\mathrm{Cr}_{2}(\mathrm{OH})_{2}(\mathrm{nta})_{2}\right]^{2-}$ anions and chiral $\left[\mathrm{Zn}\left(2,2^{\prime}-\right.\right.$ bpy $\left.)_{2}\left(\mathrm{H}_{2} \mathrm{O}\right)_{2}\right]^{2+}$ cations lead to the $3 \mathrm{D}$ NCS arrangement in the $\left[\mathrm{Zn}\left(2,2^{\prime}-\mathrm{bpy}\right)_{2}\left(\mathrm{H}_{2} \mathrm{O}\right)_{2}\right]\left[\mathrm{Cr}_{2}(\mathrm{OH})_{2}(\mathrm{nta})_{2}\right] \cdot 7 \mathrm{H}_{2} \mathrm{O}$ structure reported by Ciornea et al. (Figure 3). ${ }^{19}$

\section{CONCLUSION}

Structural analysis of I and II reveals an interesting interaction in the solid state between their constituent polar and chiral BBUs. The structure I with anions inherently nonpolar does not result in the chiral resolution. In II, $\left[\mathrm{Ni}\left(2,2^{\prime}-\mathrm{bpy}\right)_{3}\right]$ $\left(\mathrm{S}_{2} \mathrm{O}_{3}\right) \cdot 7 \mathrm{H}_{2} \mathrm{O}$, and $\left[\mathrm{Ni}\left(2,2^{\prime} \text {-bpy }\right)_{3}\right]\left(\mathrm{SO}_{4}\right) \cdot 7.5 \mathrm{H}_{2} \mathrm{O}$, the centrosymmetry is induced by the stacking of NCS layers of opposite handedness and polarity. On the other hand, the previously reported $\left[\mathrm{Zn}\left(2,2^{\prime}-\mathrm{bpy}\right)_{2}\left(\mathrm{H}_{2} \mathrm{O}\right)_{2}\right]\left[\mathrm{Cr}_{2}(\mathrm{OH})_{2}(\mathrm{nta})_{2}\right] \cdot 7 \mathrm{H}_{2} \mathrm{O}$ is both polar and chiral (space group $\mathrm{P2}_{1}$ ) when the acentric anionic and cationic units adopt a 3D structure. Assembling chiral and polar BBUs of opposite charges is a promising strategy to target interactions between the acentric BBUs that preserve the chirality and polarity in the solid state. 


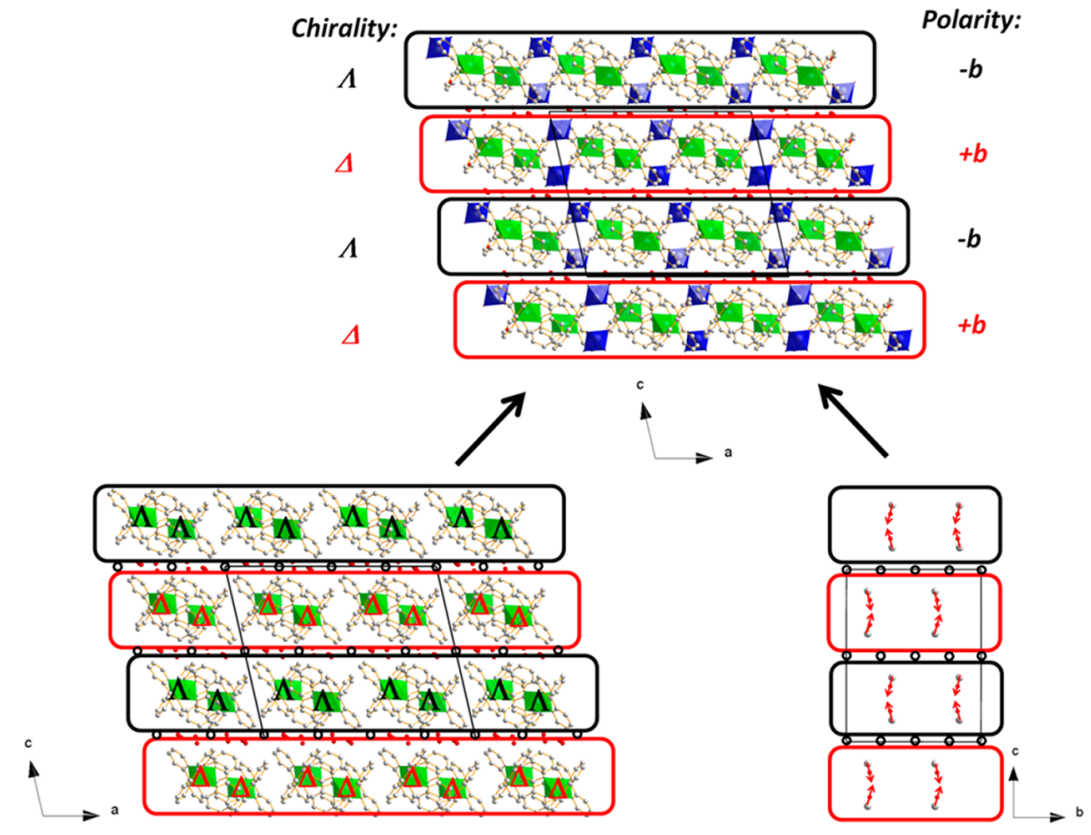

Figure 4. Chirality and polarity in compound II. The handedness of chiral cations is represented by the Greek letter $\Delta$ or $\Lambda$, and the polarity of anions is aligned along $b$ or $-b . \mathrm{H}$ atoms have been removed for clarity. Green octahedra represent late-transition-metal-centered units. Blue octahedra represent early-transition-metal-centered units. Black circles represent the inversion centers.

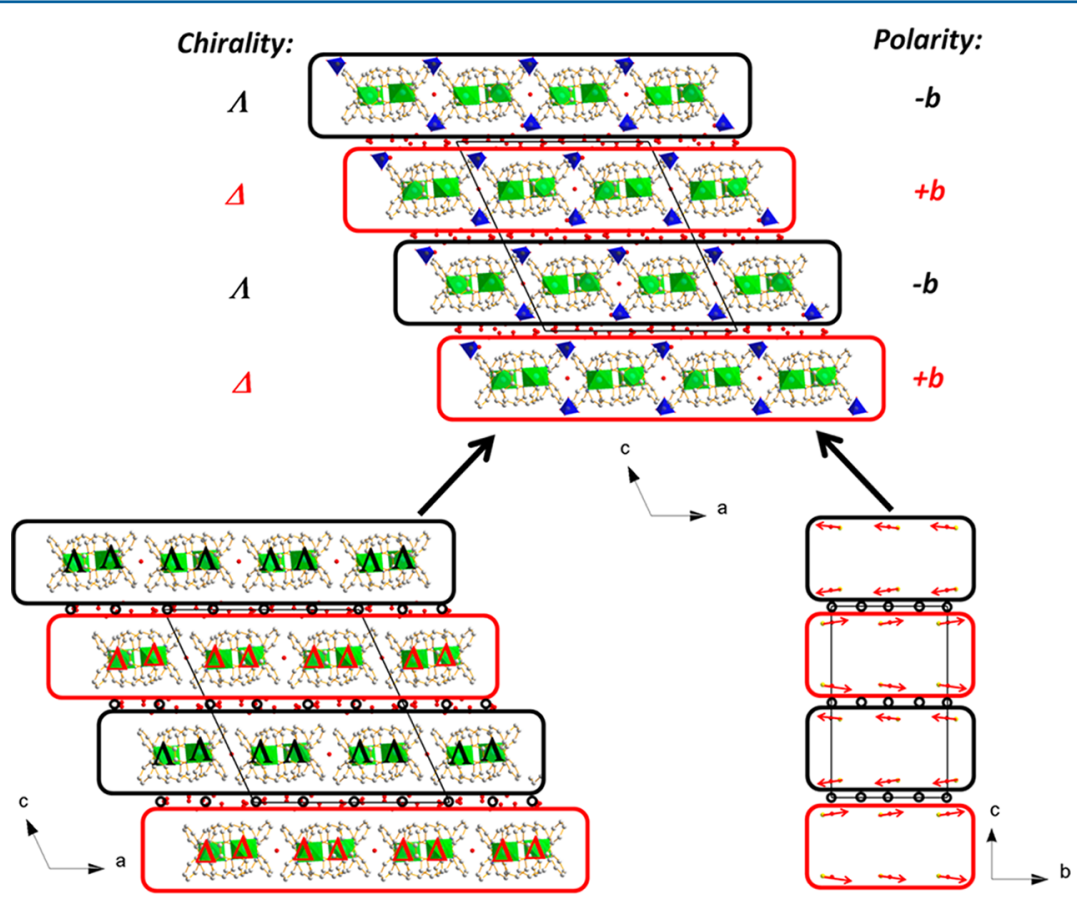

Figure 5. Chirality and polarity in $\left[\mathrm{Ni}\left(2,2^{\prime} \text {-bpy }\right)_{3}\right]\left(\mathrm{SO}_{4}\right) \cdot 7 \cdot 5 \mathrm{H}_{2} \mathrm{O}{ }^{22}$ The handedness of chiral cations is represented by the Greek letter $\Delta$ or $\Lambda$, and the polarity of anions is aligned along $b$ or $-b$. $\mathrm{H}$ atoms have been removed for clarity. Green octahedra represent late-transition-metal-centered units. Blue tetrahedra represent early-transition-metal-centered units. Black circles represent the inversion centers.

\section{ASSOCIATED CONTENT}

\section{S Supporting Information}

FTIR spectra and X-ray crystallographic files in CIF format for compounds I and II. This material is available free of charge via the Internet at http://pubs.acs.org.

\section{AUTHOR INFORMATION}

\section{Corresponding Author}

*E-mail: krp@northwestern.edu. Tel.: +1-847-491-3505.

\section{Notes}

The authors declare no competing financial interest.

\section{ACKNOWLEDGMENTS}

This work was supported by funding from the National Science Foundation (Solid State Chemistry Award DMR-1005827). The single-crystal X-ray data were acquired at Northwestern University's Integrated Molecular Structure Education and Research Center; we thank Charlotte Stern and Amy Sarjeant 
for discussions regarding the crystal structures. We additionally thank Martin D. Donakowski for discussions regarding the crystal structures.

\section{REFERENCES}

(1) Halasyamani, P. S.; Poeppelmeier, K. R. Chem. Mater. 1998, 10, 2753-2769.

(2) Gutnick, J. R.; Muller, E. A.; Narducci Sarjeant, A.; Norquist, A. J. Inorg. Chem. 2004, 43, 6528-6530.

(3) Muller, E. A.; Cannon, R. J.; Sarjeant, A. N.; Ok, K. M.; Halasyamani, P. S.; Norquist, A. J. Cryst. Growth Des. 2005, 5, 19131917.

(4) Veltman, T. R.; Stover, A. K.; Narducci Sarjeant, A.; Ok, K. M.; Halasyamani, P. S.; Norquist, A. J. Inorg. Chem. 2006, 45, 5529-5537.

(5) Hubbard, D. J.; Johnston, A. R.; Casalongue, H. S.; Sarjeant, A. N.; Norquist, A. J. Inorg. Chem. 2008, 47, 8518-8525.

(6) Glor, E. C.; Blau, S. M.; Yeon, J.; Zeller, M.; Shiv Halasyamani, P.; Schrier, J.; Norquist, A. J. J. Solid State Chem. 2011, 184, 1445-1450.

(7) Peters, D.; Miethchen, R. J. Fluorine Chem. 1996, 79, 161-165.

(8) Bertolini, J. C. J. Emerg. Med. 1992, 10, 163-168.

(9) Segal, E. B. Chem. Health Saf. 2000, 7, 18-23.

(10) Harrison, W. T. A.; Nenoff, T. M.; Gier, T. E.; Stucky, G. D. Inorg. Chem. 1993, 32, 2437-2441.

(11) Halasyamani, P.; Willis, M. J.; Stern, C. L.; Poeppelmeier, K. R. Inorg. Chim. Acta 1995, 240, 109-115.

(12) Maggard, P. A.; Stern, C. L.; Poeppelmeier, K. R. J. Am. Chem. Soc. 2001, 123, 7742-7743.

(13) Maggard, P. A.; Kopf, A. L.; Stern, C. L.; Poeppelmeier, K. R.; Ok, K. M.; Halasyamani, P. S. Inorg. Chem. 2002, 41, 4852-4858.

(14) SAINT-Plus, version 6.02A; Bruker Analytical X-ray Instruments: Madison, WI, 2000.

(15) Sheldrick, G. M. SADABS; University of Göttingen: Göttingen, Germany, 2002.

(16) Altomare, A.; Burla, M. C.; Camalli, M.; Cascarano, G. L.; Giacovazzo, C.; Guagliardi, A.; Moliterni, A. G. G.; Polidori, G.; Spagna, R. J. Appl. Crystallogr. 1999, 32, 115-119.

(17) Sheldrick, G. Acta Crystallogr., Sect. A 2008, 64, 112-122.

(18) Spek, A. L. PLATON; Utrecht University: Utrecht, The Netherlands, 2001.

(19) Ciornea, V.; Mingalieva, L.; Costes, J.-P.; Novitchi, G.; Filippova, I.; Galeev, R. T.; Shova, S.; Voronkova, V. K.; Gulea, A. Inorg. Chim. Acta 2008, 361, 1947-1957.

(20) Dixit, N.; Goto, K.; Mishra, L.; Roesky, H. W. Polyhedron 2010, 29, 1299-1304.

(21) Ye, N.; Chen, Q.; Wu, B.; Chen, C. J. Appl. Phys. 1998, 84, 555558.

(22) Wada, A.; Sakabe, N.; Tanaka, J. Acta Crystallogr., Sect. B 1976, 32, 1121-1127.

(23) Freire, E.; Baggio, S.; Mombru, A.; Baggio, R. Acta Crystallogr., Sect. C 2000, 56, 541-543.

(24) Castellucci, E.; Angeloni, L.; Neto, N.; Sbrana, G. Chem. Phys. 1979, 43, 365-373.

(25) Rajan, O. A.; Chakravorty, A. Inorg. Chem. 1981, 20, 660-664.

(26) Welk, M. E.; Norquist, A. J.; Arnold, F. P.; Stern, C. L.; Poeppelmeier, K. R. Inorg. Chem. 2002, 41, 5119-5125.

(27) Kunz, M.; Brown, I. D. J. Solid State Chem. 1995, 115, 395-406.

(28) Pietraszko, A.; Bronowska, W.; Wojciechowska, A.; Staszak, Z.; Cieslak-Golonka, M. Polym. J. Chem. 2002, 76, 309-324.

(29) Maggard, P. A.; Kopf, A. L.; Stern, C. L.; Poeppelmeier, K. R. CrystEngComm 2004, 6, 451-457. 